\title{
Tips on Publishing
}

\author{
Libby V. Morris
}

Published online: 27 January 2012

(C) Springer Science+Business Media, LLC 2012

I am pleased to report that the interest in the journal of Innovative Higher Education continues to increase, and our readership and submissions are now truly global as we enter our 37 th year of publication. Since 2001, manuscript submissions to the journal have almost tripled! To accommodate this growth and to be able to accept the high quality manuscripts we receive, in 2005 we moved from producing 4 issues each year to 5; and beginning with volume 37 (which covers 2011) Springer Press has allowed us to increase the page limit for each issue. In effect, this expansion allows six to seven articles per issue rather than the standard five.

Manuscripts are first reviewed editorially before placement into the blind and peer review process. As you may imagine, the members of our editorial board, which is made up of highly distinguished scholars, are reading more manuscripts each year. In addition, we use invited guest reviewers, primarily for two reasons: 1) a particular area of expertise would be desirable in reviewing a manuscript, and/or 2) our own board members are overloaded at a particular time. I am writing about the numbers and our editorial board and review process because our acceptance rate is now at about $15 \%$; and I thought it might be useful, especially for emerging scholars, to know some of the reasons manuscripts are rejected and to gain insight into the "system" of comments from reviewers. Some of the problems with manuscripts may be easily fixed; others, not so.

Common problems include the following, and I include sample reviewer comments.

- Failure to follow the page limitations of 20-25 pages. Why should our reviewers wade through 35-40 pages to get to the substance of a manuscript? Upon receiving an overly lengthy manuscript, we must then request that the manuscript be shortened if the manuscript content is deemed appropriate and of interest. Reviewer's comment: "Way too long-37 pp. we don't need this one!"

- Failure to follow APA guidelines. I know it is so much more interesting to write creatively than to cite and reference correctly. However, both of these problems take

L. V. Morris $(\bowtie)$

Institute of Higher Education, University of Georgia, 102 Meigs Hall, Athens, GA 30602-6772, USA

e-mail: lvmorris@uga.edu 
extra time for our reviewers and the amazing co-editor, Kay Gillespie, as she closely edits the manuscripts before final submission.

Guidelines and tips for authors may be found at http://ihe.uga.edu/publications/ innovative-higher-education/submission-guidelines, and we encourage potential authors to review them closely before submitting a manuscript. The more attentive one is to detail, the better the impression made upon editors and then reviewers.

Other, more serious problems, which generally cannot be remedied for our journal, include the following.

- Inappropriate subject matter and content for the journal. The journal seeks to publish articles that are relevant to higher education broadly and may be considered innovative. Narrow disciplinary research, replication studies, and routine investigation of longstanding educational practices are generally rejected.

Reviewer's comment: "Since this does not contribute to knowledge about student engagement overall in higher education, I think it would be better placed in a journal that focuses on student ...."

- "Reflective Essays". While an individual's story of how they set-up an educational activity and what they learned might be interesting to some, our reviewers do not consider this as appropriate research for Innovative Higher Education.

Reviewer's comment: "This manuscript is not ready for publication in this journal. It reads like a journal of what you did, not a scholarly writing."

- Inadequacies in organization and style. Over time, most of us learn that our writing is not perfect; and we take feedback as part of the improvement process. If the manuscript is difficult to read because of poor word choices, clumsy sentences, or poor organization, the reviewer is likely to question the substance, too. A good practice is to read the manuscript aloud to yourself. Good scholarship is reflected by the care one takes in writing.

Reviewers' comments: "Examples of the awkwardness of the writing include the following: The first sentence begins with 'When this program began,...' however, the reader does not know anything yet about what program is being referenced." "The review of the literature is too long and does not seem to be leading to your study or a specific purpose."

- Weaknesses in research methods and design. Manuscripts should meet the highest standards for posing research questions, collecting, analyzing and interpreting data. Incomplete and inadequate methods are easily identified.

\section{Reviewers' comments:}

"There are claims unsubstantiated by the evidence or incompletely developed or thought out, such as...." "The manuscript could be improved by 1) a more meaningful literature review, 2) clear statement of the research purpose or research questions, 3) a detailed explanation of the research methodology and limitations, and 3) findings that expand current knowledge of the issues covered in this manuscript." "You need to clearly state the purpose of your paper."

I am pleased to say that our reviewers do a great job in giving feedback, as shown by the following comment in an email from an author whose manuscript was rejected: 
Though I am disappointed that the article was not accepted, I thank you for your kind words. If it is possible, please also pass my thanks on to the reviewer who went above and beyond in responding to our work. He or she was thorough and insightful in responding to the points we made, and the review came across as constructive. I have never before been inspired to keep working by a rejection. It's clear that the reviewer has a gift for commentary, and his or her students must be very lucky indeed.

In summary, we recommend that you ask your most demanding colleague to read your work before it is sent out and that you be attentive to details and the expectations and requirements of the journal to which you are submitting your manuscript. We seek to have our review process as streamlined as possible and are generally able to render judgment about a manuscript that has been placed into our blind review process within two months. Above all, we want you to know that we seek to treat authors with all possible courtesy and to respond to questions or submissions as quickly as possible. Thank you for considering Innovative Higher Education, and best wishes to you as you develop manuscripts to share your work with other scholars. 